\title{
THE METABOLIC RESPONSE TO BURNS
}

\author{
By ERIC REISS, ${ }^{1}$ ELINOR PEARSON, AND CURTIS P. ARTZ WITH THE ASSISTANCE of \\ BERNARD BALIKOV
}

(From the Surgical Research Unit, Brooke Army Medical Center, Fort Sam Houston, Texas)

(Submitted for publication January 3, 1955; accepted September 1, 1955)

Since Cuthbertson first published his important investigations, the metabolic response to trauma has been the subject of continuous study in many disciplines of medicine (1-8). An impressive body of knowledge has been accumulated with respect to changes in plasma electrolyte concentrations, urinary electrolyte excretion, body composition, and adrenocortical activity.

There is general agreement that injury is accompanied by an increased excretion of nonprotein nitrogenous products, but the importance of this phenomenon, its interpretation in terms of body economy, and its therapeutic implications remain the subject of controversy $(4,5,7)$. On the basis of the nitrogen-sulfur and nitrogen-phosphorus ratios in the urine of rats with fractures, Cuthbertson concluded in his earlier studies that the increased excretion of nitrogen after fractures results chiefly from muscle catabolism (1). Howard and Mason, on the other hand, were unable to correlate nitrogen balance with that of potassium or phosphorus in postoperative patients (8). In burned rats, Braasch, Bell, and Levenson noted only transiently increased excretion of potassium and phosphorus while nitrogen excretion remained high for longer periods of time (9). Cope, Nathanson, Rourke, and Wilson (10) and Moore and Ball (7) recorded early negative nitrogen and positive potassium balance in burned patients.

In the present study, the balances of nitrogen, calcium, phosphorus, magnesium, potassium, sodium, and chloride were measured in burned patients for long periods of time. Information was sought about 1) the relative rates of mineral losses, and 2 ) changes in body composition.

\section{METHODS}

The data on five adults, four men and one woman, are included in this report. All were in good health be-

\footnotetext{
1 Present Address: Department of Medicine, Washington University School of Medicine, St. Louis, Missouri.
}

fore injury. Metabolic studies were begun immediately after injury. The length of individual studies varied from 60 to 180 days. The early fluid therapy given, the rationale for its use, and the details of local care have been discussed in previous publications $(11,12)$.

\section{Metabolic ward regimen}

Facilities were available for complete studies on two patients at any one time. The patients were cared for in special cubicles or in the air-conditioned side-rooms of a research ward. Air-conditioning was provided in order to minimize the losses of electrolytes through sweat. One of the authors was responsible for all aspects of treatment. Four nurses who were especially trained in metabolic technics were responsible for nursing care and collection of all specimens. The patients were weighed daily for the first two postburn weeks and twice a week thereafter. A Toledo scale was used with a special attachment for weighing patients on Stryker frames. This scale registers weights to within $114 \mathrm{gm}$. The reproducibility of weighing a patient, with or without a frame, was repeatedly tested and found to be satisfactory. When possible, allowance for weight change due to a dressing change was made by weighing patients both before and after a dressing change.

\section{Dietary regimen}

All of the food was prepared in and served from a special diet kitchen under the supervision of the research dietitian. Three menus were served in rotation, each menu supplying approximately 2000 calories, $100 \mathrm{gm}$. of protein, $250 \mathrm{gm}$. of carbohydrate, $60 \mathrm{gm}$. of fat, $50 \mathrm{mEq}$. of sodium, $75 \mathrm{mEq}$. of potassium, $22 \mathrm{mEq}$. of magnesium, $45 \mathrm{mEq}$. of chloride, $1.3 \mathrm{gm}$. of calcium, and $1.5 \mathrm{gm}$. of phosphorus. The menus consisted only of foods that can be stored or preserved in the frozen state. A dietary supplement was given in the form of a formula consisting of eggs, dried whole and skim milk, DextriMaltose ${ }^{8}$, and a flavoring agent. The supplement provided an additional 2700 calories, $100 \mathrm{gm}$. of protein, $473 \mathrm{gm}$. of carbohydrate, $85 \mathrm{gm}$. of fat, $130 \mathrm{mEq}$. of sodium, $120 \mathrm{mEq}$. of potassium, $135 \mathrm{mEq}$. of chloride, 22 $\mathrm{mEq}$. of magnesium, $2.4 \mathrm{gm}$. of calcium, and $2.7 \mathrm{gm}$. of phosphorus. If a patient ingested all of the menu and the supplement, he received approximately 4700 calories and $200 \mathrm{gm}$. of protein. The following vitamins were given in capsule form: ascorbic acid-1000 mg.; thiamin hydrochloride $-60 \mathrm{mg}$; riboflavin- $40 \mathrm{mg}$.; nicotinamide $-200 \mathrm{mg}$.; and calcium pantothenate- $40 \mathrm{mg}$. A serious attempt to achieve constancy of intake was not made 
because of the critical nature of the patients' illness. The patients were encouraged to eat as much of the total diet as possible. The supplement was given between meals during the day and at intervals during the night. The intakes that were achieved can therefore be considered a reflection of appetite, a variable that may be interpreted in terms of the natural history of convalescence from a severe burn.

A detailed report on food analyses has been presented elsewhere (13). Storage facilities for food were available for studies of 6 to 8 weeks' duration. Sample diets, prepared and cooked in the same manner in which they were served to patients, were analyzed periodically. Each of the menus was analyzed three to six times from each lot of food. Since it was demonstrated that the mineral content was significantly different in various lots of food, the mean of the analyses of a particular lot was used for calculation of the intake during the time when this lot was served. The composition of the formula was determined from the mean of repeated analyses. The volume of formula ingested was carefully measured. Uneaten foods (rejects) were pooled for individual metabolic periods and then analyzed.

Salt was not used for cooking, and the patients salted their own food from a salt shaker containing a carefully weighed amount of anhydrous sodium chloride. Food was served under close supervision of a member of the staff to avoid careless spillage of salt.

\section{Collection, preparation, and analysis of specimen}

The intake and urinary excretion of all minerals were measured in 24-hour metabolic periods for the first 2 to 3 weeks and in 5-day metabolic periods thereafter. Stools were pooled in 10-day periods from the beginning of the study. Dressings were pooled in convenient periods, the length of which was determined by the exigency of treatment in particular patients. During the early parts of a study, an effort was made to time dressing changes according to metabolic periods, but this practice proved too cumbersome and therefore had to be abandoned.

Glacial acetic acid, $50 \mathrm{ml}$., was added to the urine collection bottles at the beginning of each 24-hour collection period. Carmine was used as a marker for stool collection periods. Cascara tablets or enemas were used at the end of stool collection periods, and a distinct separation of stools into periods was usually possible. For unknown reasons, recovery of the carmine proved diffcult in the early postburn period even though large quantities of carmine were given. When distinct stool separations were not feasible, the first stool collection period was extended to 20 days and occasionally even longer. The dressings were thoroughly washed in large washing machines, and aliquots of the washings were analyzed.

All samples were prepared and analyzed by methods that have been previously described (13).

To test the adequacy of the metabolic regimen in general, three normal subjects were observed for four 5-day periods each. They were found to be essentially in equilibrium with respect to all constituents studied.

\section{Computation of balances and method of charting}

Balances were computed from all sources of intake and output. Electrolyte solutions, which were given in large volumes during the early postburn period, were not analyzed, and the composition as given by the manufacturer (volume and concentration) was used in calculating the intake from this source. Since plasma proteins enter the metabolic pool more rapidly than erythrocyte protein, nitrogen intake derived from whole blood transfusions was computed on the basis of the plasma protein content only; erythrocyte nitrogen was not counted as part of the intake. For estimating the mineral content of the plasma portion of whole blood, average values were used (7). Lyophilized plasma was given only rarely. The amount of whole blood given to the various patients is recorded on the metabolic correlation charts and in the Appendix. Since erythrocytes were not included in the intake, any dressings containing appreciable amounts of blood were discarded. This practice resulted in failure to measure some of the plasma proteins and minerals lost with the blood into the dressings. No allowance was made for 20 to $30 \mathrm{ml}$. of blood that were drawn daily in the first 2 to 3 weeks for a study of plasma electrolyte concentration changes. These studies will be reported separately.

For ease of interpretation, all of the data were charted on an average per day basis. The same grouping of data is used for all patients in order that a time-correlated comparison of their respective metabolic adjustment can be made visually. The day of injury is "day zero," the day after injury is the first postburn day, and so forth. The first 10 days of study are divided into a zero through second day period and a third through ninth day period. Thereafter, the balances are charted in 10-day intervals. The pooling of balances into arbitrary periods is a matter of convenience for graphic presentation. It obscures some important details, but these can be obtained from the original data. ${ }^{2}$ Nitrogen, potassium, magnesium, and phosphorus are charted approximately in the relative proportions in which these minerals are believed to be present in normal muscle. Calcium and phosphorus are charted in a ratio that approximates the calcium-phosphorus ratio of bone. Sodium and chloride are charted separately. The intake is charted from the zero line up and the output from the top of the intake line down. Solid black areas indicate negative balance below the zero line and positive balance above it. The cross-hatched areas represent exudate contribution to the output. The relative contributions of urine and feces to the output are not shown.

Four ordinate scales are applicable to the five minerals charted on the upper part of the charts. One gram of nitrogen is charted as equivalent to $3.3 \mathrm{mEq}$. of potassium and $1 / 15 \mathrm{gm}$. of phosphorus. Calcium and phosphorus are charted in a ratio of $2: 1$. For charting purposes, these ratios are convenient approximations to the

2 Detailed data are available to the reader on request: Lt. Col. Curtis P. Artz, Surgical Research Unit, Brooke Army Medical Center, Fort Sam Houston, Texas. 


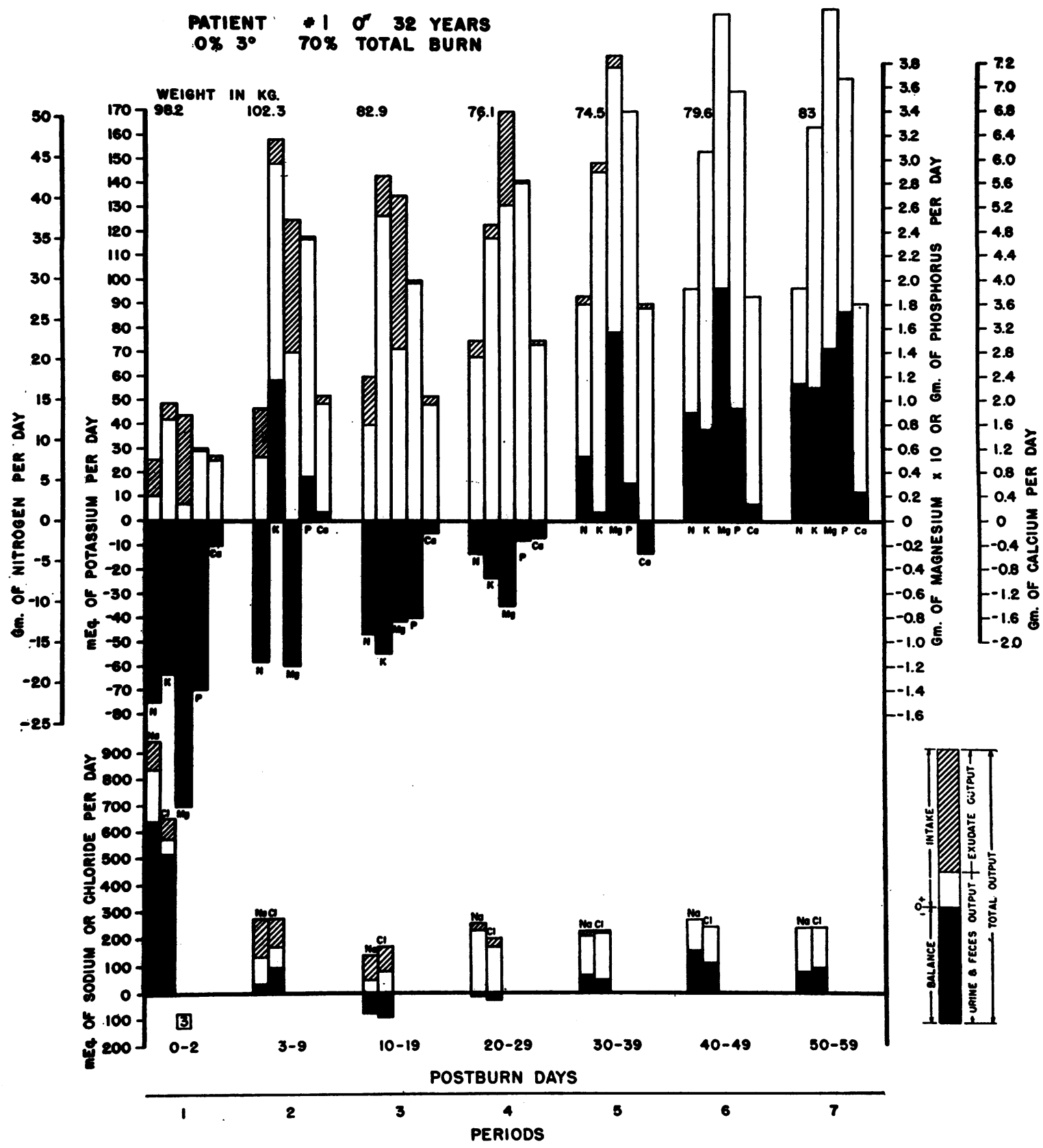

- Skin graft.

(3) Two dressing changes under general anesthesia.

One unit of blood transfusion.

factors given by Reifenstein, Albright, and Wells (14). In Table I, the conversion factors recommended by these authors were used in computing theoretical balances, except that $3 \mathrm{mEq}$. rather than $2.7 \mathrm{mEq}$. of potassium were considered equivalent to $1 \mathrm{gm}$. of nitrogen. The conversion factor for intracellular magnesium is not well established. According to Baldwin, Robinson, Zierler, and Lilienthal (15) $0.61 \mathrm{mEq}$. (7.3 mg.) of magnesium correspond to $1 \mathrm{gm}$. of non-collagenous muscle nitrogen. Since $1 / 15 \mathrm{gm}$. ( $67 \mathrm{mg}$.) of phosphorus corresponds to $1 \mathrm{gm}$. of intracellular nitrogen, it was considered adequate for purposes of visual representation to use the same ordinate scale for "magnesium times 10 " as for "phosphorus." 


\section{RESULTS}

\section{Balances and Correlations}

\section{Nitrogen balance}

In patients 1 through 5 , the duration of negative nitrogen balance (catabolic phase) was 28, $36,31,30$, and 15 days, respectively (Figures 1-6). Negative nitrogen balance resulted from the very large excretion of urinary nitrogen as well as from a low dietary intake. The urinary nitrogen was much higher in the four men than in the woman (patient 4). There were large fluctuations from day to day in the amount of urinary nitrogen excreted, and the excretion rate tended toward a maximum at the end of the first postburn week. As the nitrogen balance approached equilibrium and became positive, the urinary nitrogen was generally low and, occasionally, exceptionally low. In patient 4 , for example, the average urinary nitrogen was $5.9 \mathrm{gm}$. on an intake of $10.3 \mathrm{gm} .45$ to 49 days after injury. The greatest urinary nitrogen loss on any one day occurred in patient 5, who excreted $36.9 \mathrm{gm}$. of nitrogen on the seventh postburn day on an intake of $18.8 \mathrm{gm}$. of nitrogen. Urinary nitrogen excretion of 25 to $30 \mathrm{gm}$. per day was commonly

PATIENT 2 O 24 YEARS

$20 \% 3^{\circ} 45 \%$ TOTAL BURN

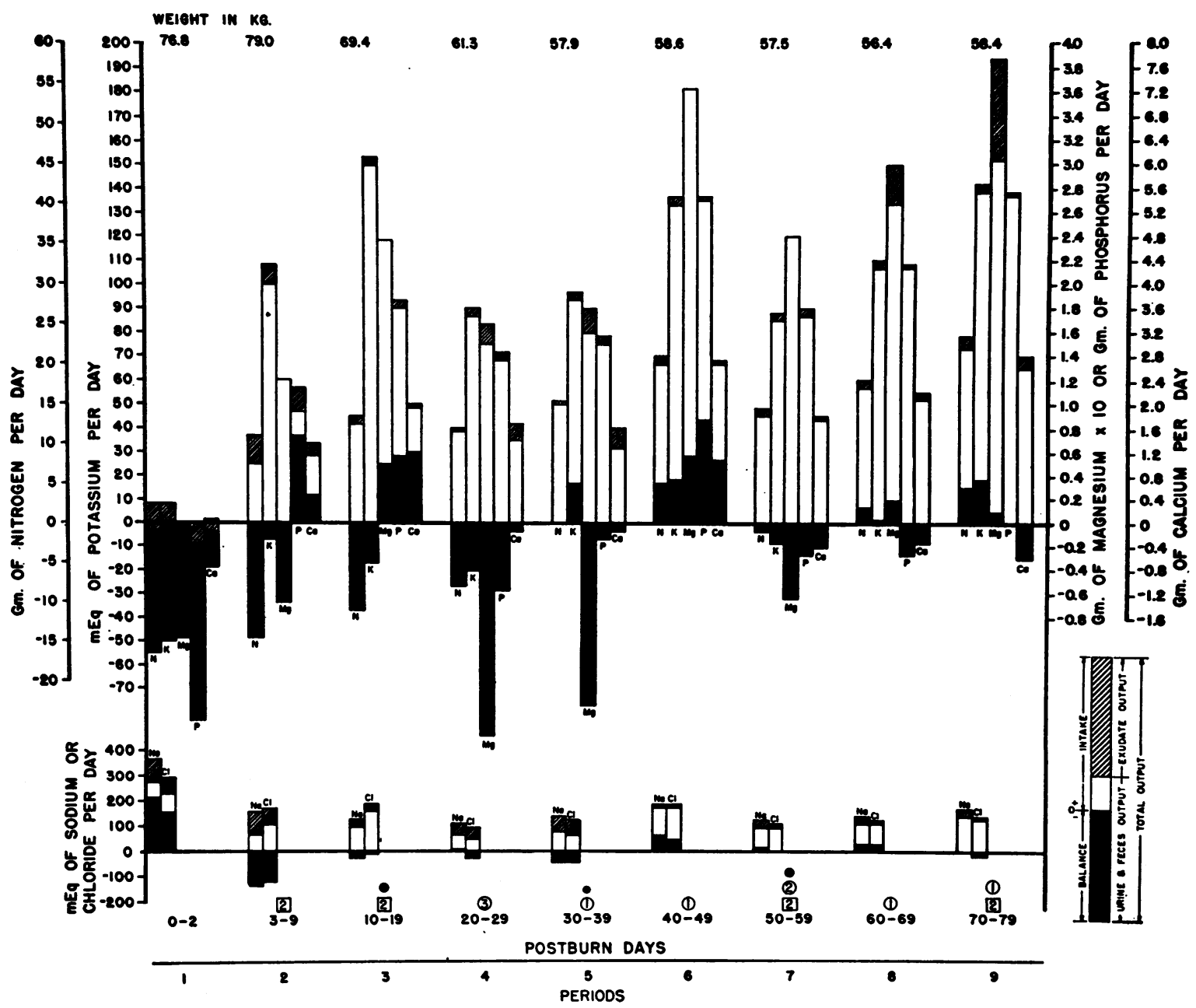

Fig. 2A. Metabolic Correlation Chart, $0^{\circ}$ to 79 Days, Patient 2 
PATIENT 2 \% 24 YEARS

$20 \% 3^{\circ} 45 \%$ TOTAL BURN

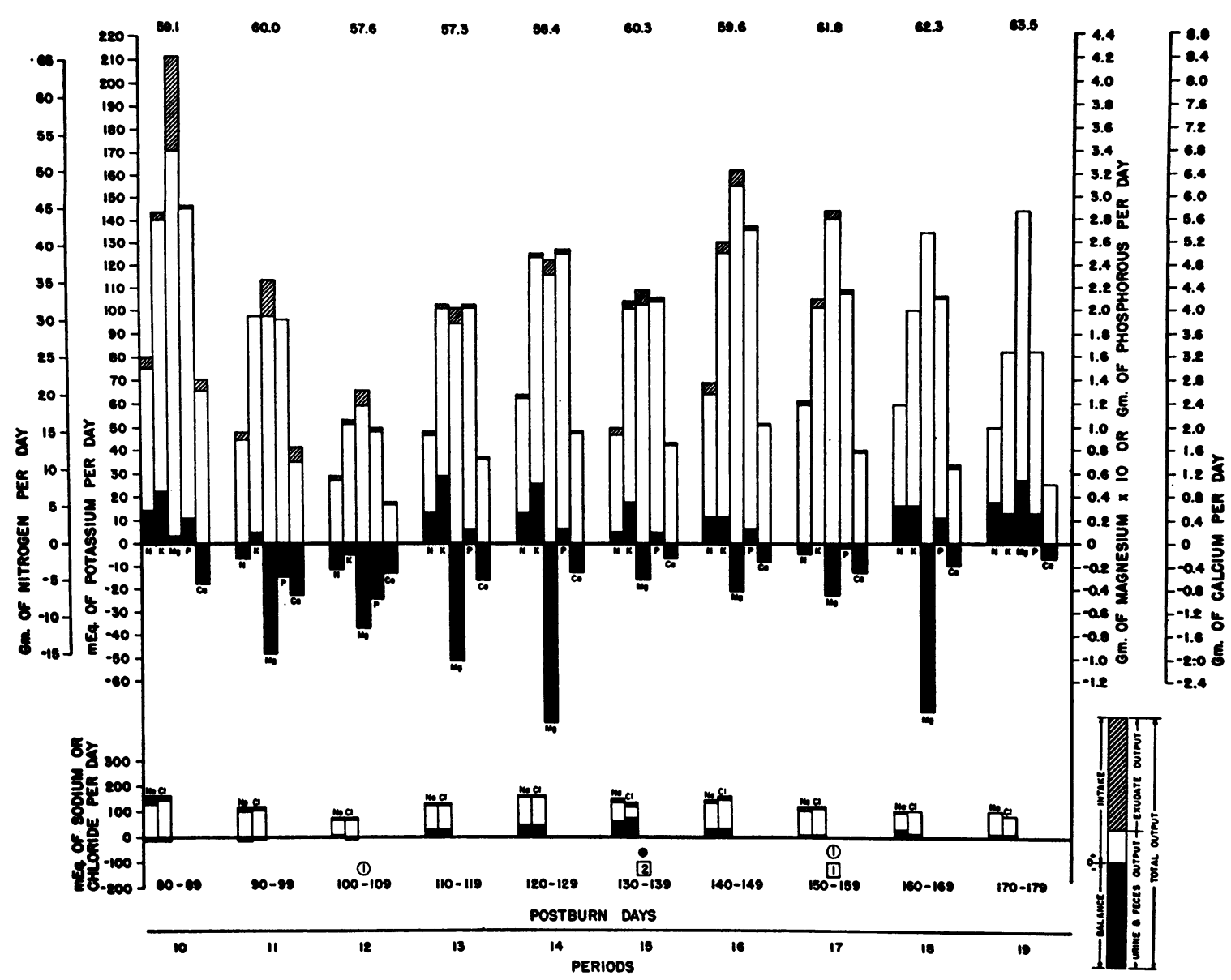

Fig. 2B. Metabolic Correlation Chart, 80 to 179 Days, Patient 2

observed in the first postburn week at a time when intakes were generally low.

The magnitude of positive nitrogen balance during the anabolic phase (period of predominantly positive nitrogen balance) varied greatly. The highest rate of nitrogen storage occurred in patient 1 whose average nitrogen retention was 20 gm. per day between the 46th and 55th postburn days. ${ }^{3}$

There was a significant positive correlation between nitrogen intake and fecal nitrogen $(r=$ $0.58 ; \mathrm{P}<0.001)$. However, the regression coefficient was low $(0.05)$, and the fecal nitrogen

3 The blood nonprotein nitrogen concentration was measured at frequent intervals in all patients. Azotemia was not observed at any time. was rarely outside the range of 1 to $2 \mathrm{gm}$. per day. The exudate nitrogen, on the other hand, was highly variable and contributed a substantial fraction to the total output. Exudate nitrogen decreased as wound closure was achieved. The wounds of patient 4 deteriorated progressively, and this was reflected by a high nitrogen content in the exudate. On several occasions, the exudate nitrogen accounted for more than 50 per cent of the total nitrogen output.

\section{Potassium-nitrogen correlation.}

In the immediate postburn period, potassium balance was negative in all patients, and the potassium-nitrogen ratio of the balances approximated the value expected by whole tissue catabolism. 
This early potassium excretion was followed by relative potassium retention, which is defined as less potassium excretion than would be expected if the negative nitrogen balance reflected whole tissue breakdown. Relative potassium retention occurred irrespective of the level of potassium intake. In the latter part of the catabolic phase, potassium balance again tended toward the expected value. In patients 2,3 , and 4 , potassium balance was somewhat less negative than expected by nitrogen balance; in patient 1 it was more negative. The difference in response can be explained by reference to Figure 6 , where it is seen that the unusually large amounts of po- tassium given to patient 1 in the early postburn period were temporarily retained in the body and excreted during the late catabolic phase.

In the anabolic phase, potassium balance was rather well correlated with nitrogen balance. Although marked fluctuations occurred between various periods and various patients, deviations from the expected ratio were not consistent either in magnitude or direction.

Large quantities of potassium were lost via the exudate. Except for relatively minor fluctuations, exudate potassium declined as wound closure proceeded. In patient 4 , serious deterioration of the status of the wounds in late stages of the study

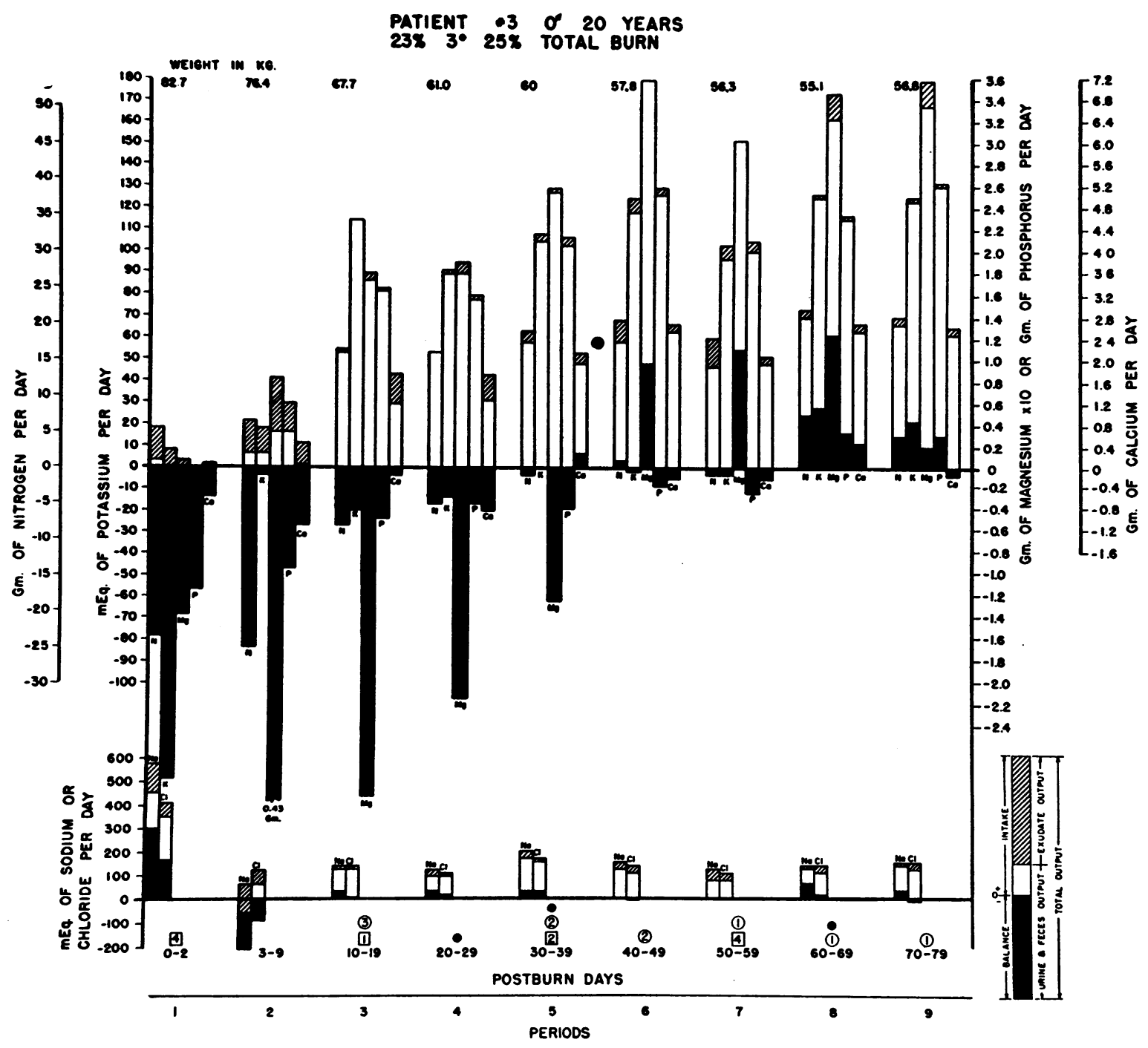

Fig. 3a. Metabolic Correlation Chart, 0 to 79 Days, Patient 3 


\section{PATIENT $3 \sigma 20$ YEARS \\ $23 \% 3^{\circ} 25 \%$ TOTAL BURN}

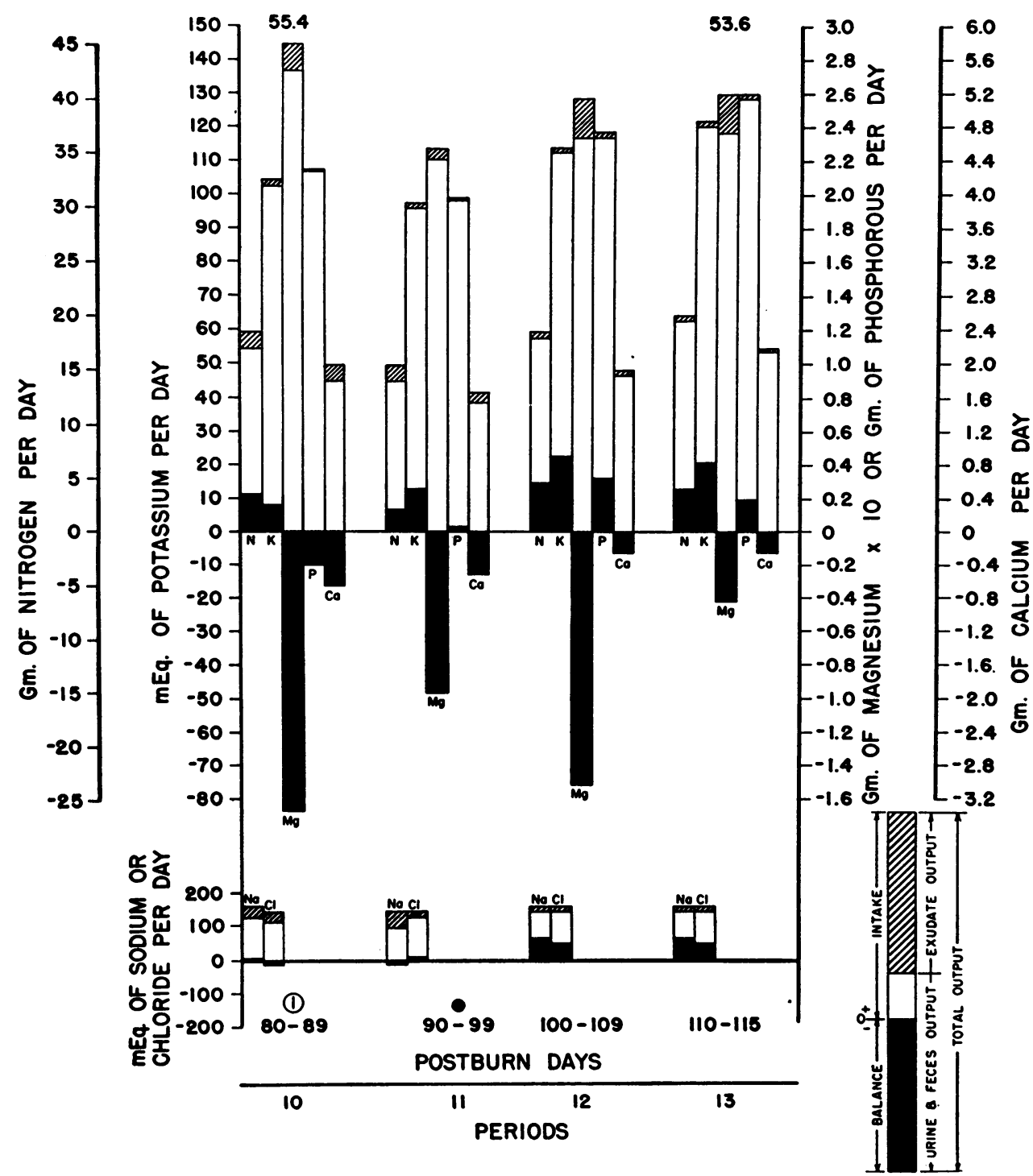

Fig. 3b. Metabolic Correlation Chart, 80 to 115 Days, Patient 3

was associated with a high potassium content of the exudate, and on several occasions as much as 40 per cent of the total potassium excretion occurred via the exudate.

Correlation of calcium, phosphorus, and other mineral balances

A rapid, approximate estimate of the theoretical phosphorus balance based on calcium and ni- trogen can be obtained visually from the charts by adding the observed nitrogen and calcium balances in an algebraic manner. Similarly, the theoretical nitrogen balance based on calcium and phosphorus can be obtained by algebraically subtracting the observed calcium from the observed phosphorus balance. The theoretical potassium balance based on calcium and phosphorus equals the theoretical nitrogen balance based on these constituents. 
In the early postburn period, the theoretical phosphorus balance based on calcium and nitrogen consistently deviated from the observed phosphorus balance, so that the observed phosphorus loss was smaller than that predicted on the basis of the nitrogen and calcium balances. During the same interval, the theoretical potassium balance based on nitrogen deviated markedly and consistently from the observed potassium balance so that the observed potassium excretion was less than that predicted on the basis of the nitrogen balance. Thus, the deviations from the expected values of both the phosphorus and potassium balances coincided in time as well as direction. In subsequent periods, there was, in general, agreement between the theoretical and observed phosphorus balances, both at times when nitrogen balance was positive and when it was negative. During many of the study periods, the theoretical phosphorus balance was in better agreement with the observed potassium balance than with the observed nitrogen balance.

\section{Magnesium balance and correlation}

In order to establish a baseline for comparison, three normal subjects were studied for four 5-day metabolic periods each. The intake was constant at approximately $26 \mathrm{mEq}$. of magnesium per day. On the average, 25 per cent of the ingested magnesium was excreted in the urine, the remainder

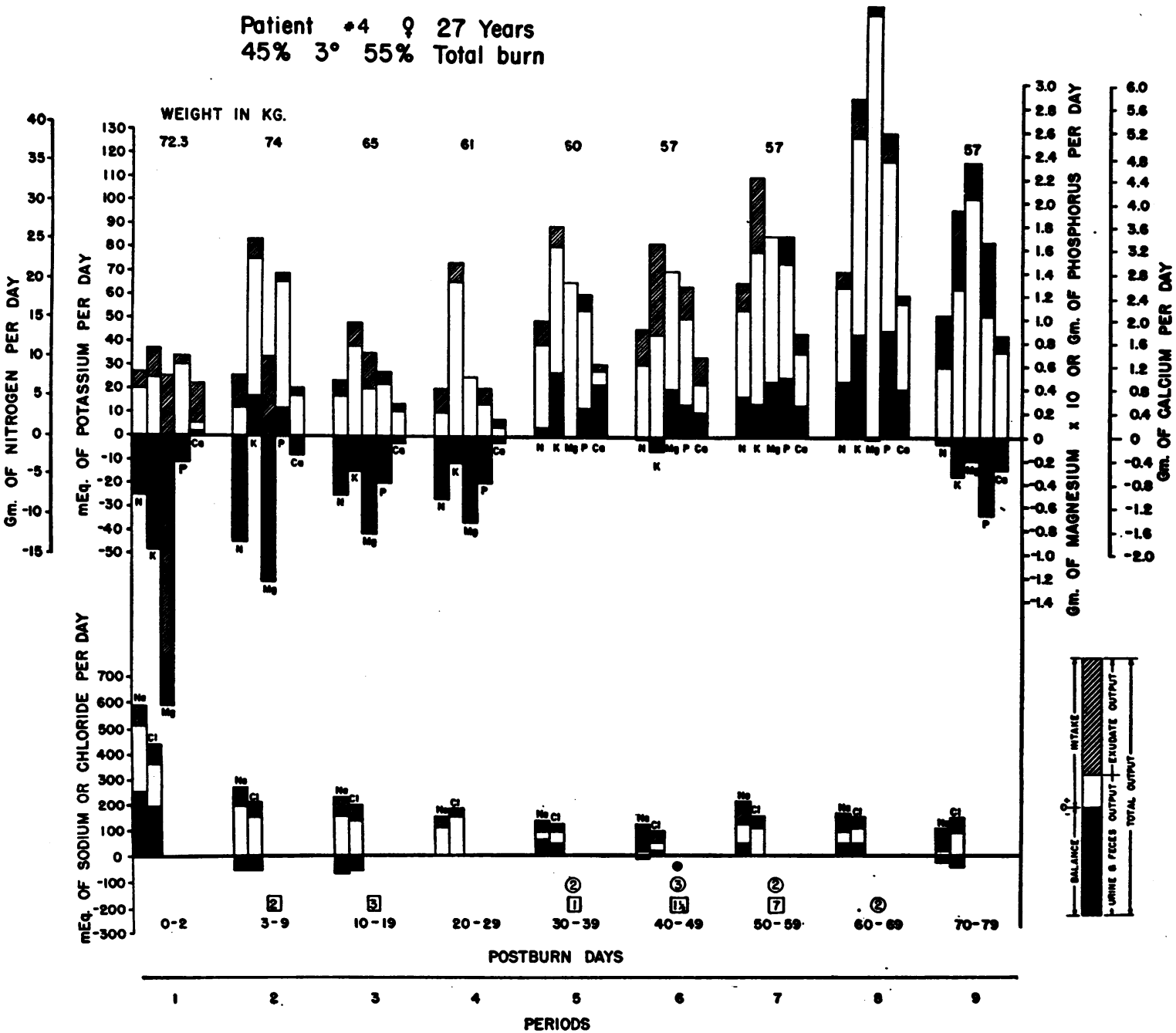

Fig. 4. Metabolic Correlation Chart, Patient 4 
PATIENT - 5 of 30 YRS.

$1583^{\circ} 358$ TOTAL BURM

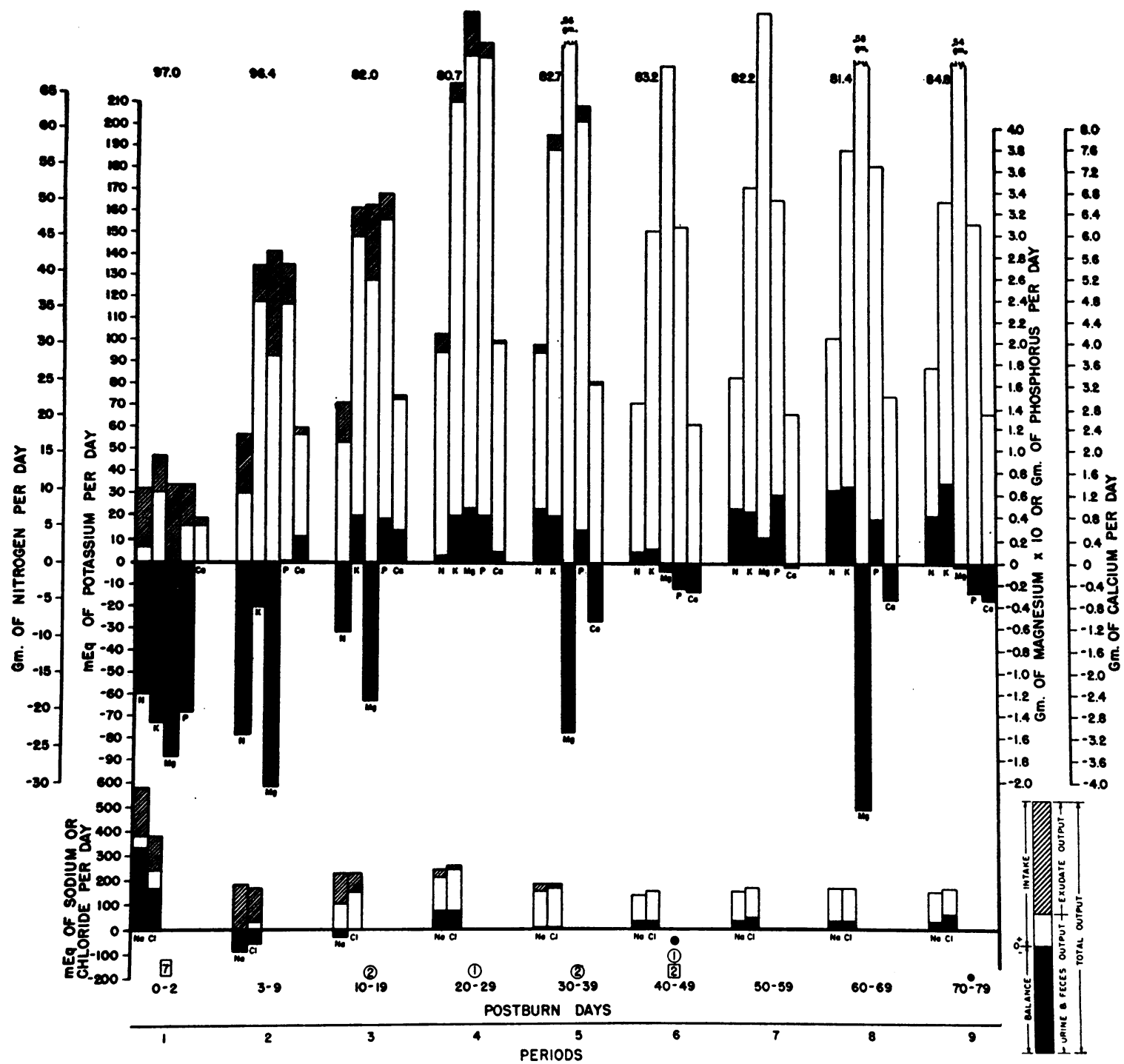

Fig. 5. Metabolic Correlation Chart, Patient 5

being excreted in the feces. The data in individual subjects were highly variable owing to changes in fecal excretion. The urinary magnesium was quite constant.

In the patients, the fecal magnesium also tended to vary widely while the urinary magnesium was more nearly constant. For the 5-day metabolic periods, the mean and standard deviation of the urinary magnesium expressed as $\mathrm{mEq}$. were $6.8 \pm$ $3.3 ; 7.4 \pm 2.0,5.1 \pm 2.1,2.9 \pm 0.9$, and $10.1 \pm$ 2.1 for the 5 patients, respectively. In patients 1 and 4 , the nitrogen and magnesium balances were well correlated. In the remaining patients, the nitrogen and magnesium balances tended to be in the same direction. The unusually large negative magnesium balance recorded in some of the study periods resulted from large fecal excretion in nearly every instance.

\section{Sodium and chloride}

The sodium and chloride balances were strongly positive in the early postburn period. These posi- 
tive balances are a result of the large amounts of these ions given in an effort to keep pace with the obligatory edema that is characteristic of recent burns. The exudate always contributed a large and important fraction of the total sodium and chloride output during this early period, and failure to take account of this important route of electrolyte excretion would result in paradoxically large positive balances. The loss of these electrolytes through the sweat was large in all of the patients. Burned patients are more comfortable in warm than in moderately cool surroundings. Air- conditioning, which was available, was poorly tolerated and could be used only rarely.

\section{Changes in Body Composition}

\section{Whole tissue}

If the early negative nitrogen balance is a reflection of whole tissue catabolism, the magnitude of whole tissue loss was very great in some of the patients. If $1 \mathrm{gm}$. of nitrogen is considered equivalent to $30 \mathrm{gm}$. of tissue, the patients lost between $8.2 \mathrm{~kg}$. and $11.7 \mathrm{~kg}$. of lean body tissue

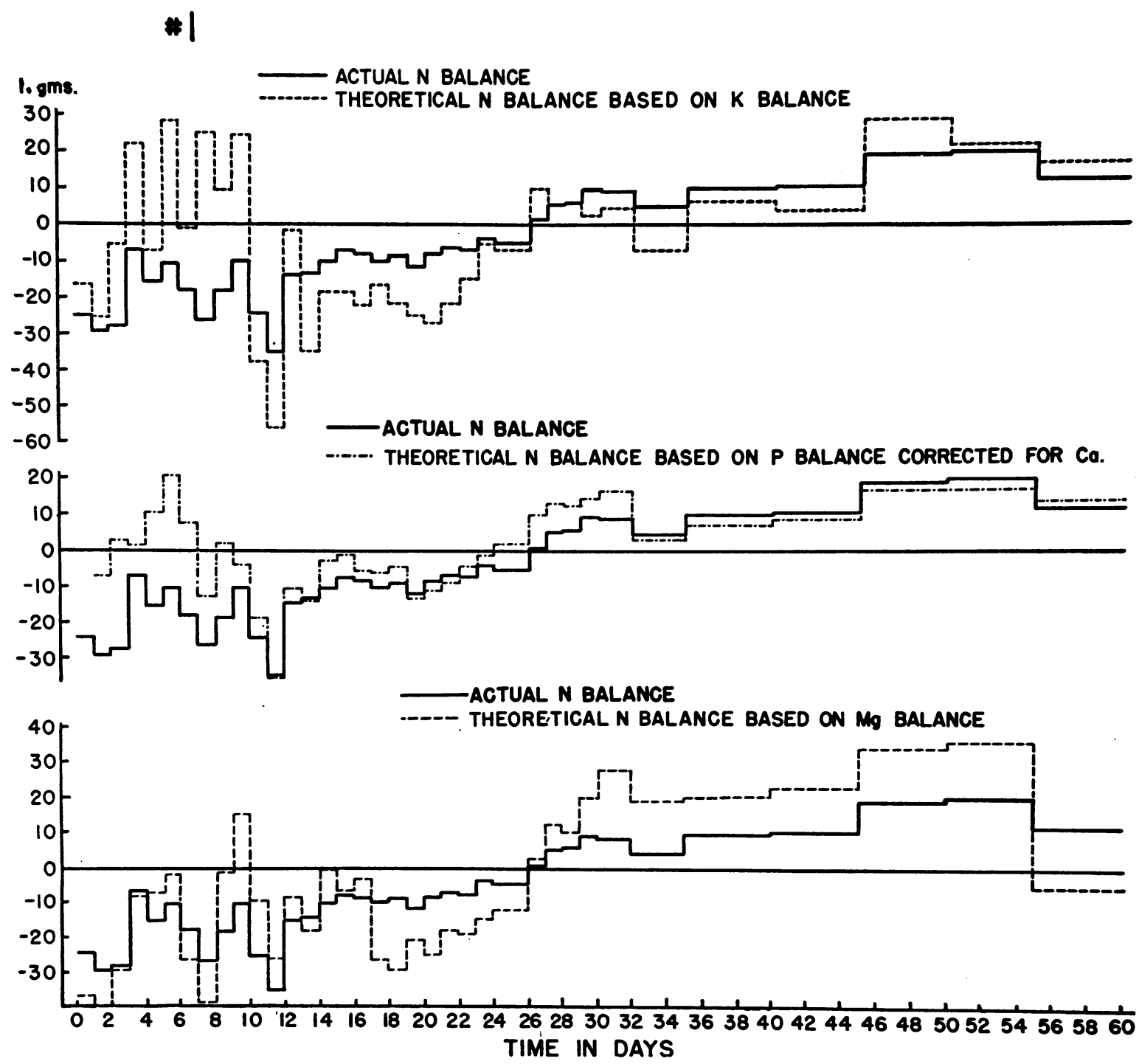

Fig. 6. Comparison Between the Observed Theoretical Nitrogen Balances Based on the Balances of Potassium, Phosphorus and Calcium, and Magnesium (Patient 1)

Note the early, relative retention of potassium and phosphorus. 
TABLE I

Cumulative observed and theoretical nitrogen balances during catabolic and anabolic phases

\begin{tabular}{|c|c|c|c|c|c|c|c|c|c|c|c|c|}
\hline \multicolumn{7}{|c|}{ Potassium } & \multicolumn{6}{|c|}{ Phosphorus } \\
\hline Patient & $\begin{array}{c}\text { Dura- } \\
\text { tion of } \\
\text { phase }\end{array}$ & $\begin{array}{c}\text { Cumula- } \\
\text { tive N } \\
\text { balance }\end{array}$ & $\begin{array}{c}\text { Cumula- } \\
\text { tive K } \\
\text { balance }\end{array}$ & $\begin{array}{l}\mathrm{K} / \mathrm{N} \\
\text { ratio }\end{array}$ & $\begin{array}{c}* \\
\text { Theoretical } \\
\text { N balance }\end{array}$ & $\begin{array}{c}D^{\dagger} \\
\text { crepance }\end{array}$ & $\begin{array}{c}\text { Cumula- } \\
\text { tive P } \\
\text { balance }\end{array}$ & $\begin{array}{c}\text { Cumula- } \\
\text { tive Ca } \\
\text { balance }\end{array}$ & $\begin{array}{c}\underset{\ddagger}{\text { Proto- }} \\
\text { plasm P } \\
\text { balance }\end{array}$ & $\begin{array}{l}\text { Proto- } \\
\text { plasm } \\
\text { P/N } \\
\text { ratio }\end{array}$ & $\begin{array}{c}\text { Theoretical } \\
\text { N balance }\end{array}$ & $\begin{array}{c}\| \\
\text { Dis- } \\
\text { crepance }\end{array}$ \\
\hline & days & $g m$. & $m E q$. & $m E q . / g m$ & $g m$. & $g m$. & $g m$. & $g m$. & $g m$. & & $g m$. & $g m$. \\
\hline \multicolumn{13}{|c|}{ Catabolic Phase } \\
\hline $\begin{array}{l}1 \\
2 \\
3 \\
4 \\
5\end{array}$ & $\begin{array}{l}28 \\
36 \\
31 \\
30 \\
15\end{array}$ & $\begin{array}{l}-390 \\
-341 \\
-383 \\
-275 \\
-322\end{array}$ & $\begin{array}{l}-830 \\
-660 \\
-1010 \\
-290 \\
-440\end{array}$ & $\begin{array}{l}2.1 \\
1.9 \\
2.6 \\
1.0 \\
1.4\end{array}$ & $\begin{array}{l}-277 \\
-220 \\
-337 \\
-97 \\
-147\end{array}$ & $\begin{array}{r}113 \\
121 \\
46 \\
178 \\
175\end{array}$ & $\begin{array}{r}-13.4 \\
-7.2 \\
-18.6 \\
-7.1 \\
-7.2\end{array}$ & $\begin{array}{r}-6.4 \\
+\quad 3.8 \\
-18.6 \\
-\quad 2.7 \\
+\quad 3.9\end{array}$ & $\begin{array}{r}-10.5 \\
-8.9 \\
-10.3 \\
-\quad 5.9 \\
-\quad 8.9\end{array}$ & $\begin{array}{l}1: 37 \\
1: 38 \\
1: 37 \\
1: 47 \\
1: 36\end{array}$ & $\begin{array}{l}-158 \\
-134 \\
-154 \\
-88 \\
-134\end{array}$ & $\begin{array}{l}232 \\
207 \\
229 \\
187 \\
188\end{array}$ \\
\hline Mean & & & & 1.8 & & 126 & & & & $1: 39$ & & 209 \\
\hline \multicolumn{13}{|c|}{ Anabolic Phase } \\
\hline $\begin{array}{l}1 \\
2 \\
3 \\
4 \\
5\end{array}$ & $\begin{array}{r}33 \\
144 \\
85 \\
58 \\
65\end{array}$ & $\begin{array}{r}+415 \\
+335 \\
+293 \\
+108 \\
+347\end{array}$ & $\begin{array}{r}+1000 \\
+1760 \\
+1020 \\
+730 \\
+1720\end{array}$ & $\begin{array}{l}2.4 \\
5.2 \\
3.5 \\
6.8 \\
5.0\end{array}$ & $\begin{array}{l}+333 \\
+587 \\
+340 \\
+243 \\
+573\end{array}$ & $\begin{array}{c}(82) \\
252 \\
47 \\
135 \\
226\end{array}$ & $\begin{array}{r}+34.1 \\
+13.6 \\
+2.5 \\
+12.1 \\
+19.8\end{array}$ & $\begin{array}{l}+3.4 \\
-54.1 \\
-18.2 \\
+16.4 \\
-24.3\end{array}$ & $\begin{array}{r}+32.6 \\
+37.9 \\
+10.7 \\
+4.7 \\
+30.7\end{array}$ & $\begin{array}{l}1: 13 \\
1: 9 \\
1: 27 \\
1: 23 \\
1: 11\end{array}$ & $\begin{array}{l}+489 \\
+568 \\
+160 \\
+70 \\
+460\end{array}$ & $\begin{array}{c}74 \\
233 \\
(133) \\
38) \\
133\end{array}$ \\
\hline Mean & & & & 4.6 & & & & & & $1: 17$ & & \\
\hline
\end{tabular}

* Cumulative $\mathrm{K}$ balance divided by 3 ( $1 \mathrm{gm} . \mathrm{N}=3 \mathrm{mEq} . \mathrm{K})$.

$\dagger$ Difference between cumulative $\mathrm{N}$ balance and theoretical $\mathrm{N}$ balance based on $\mathrm{K}$ balance.

$\ddagger$ Cumulative $P$ balance - $\left(\frac{\text { Cumulative Ca balance }}{2.23}\right)$.

\& Protoplasm $\mathrm{P}$ balance times 15.

Difference between cumulative $\mathrm{N}$ balance and theoretical $\mathrm{N}$ balance based on $\mathrm{P}$ and $\mathrm{Ca}$ balances.

Figures in parentheses indicate that the expected nitrogen retention was approximated. See text for details.

during the catabolic phase. In the first 10 days, the mean nitrogen loss was $18 \mathrm{gm}$. per day, which would be equivalent to $540 \mathrm{gm}$. of whole tissue loss per day.

During the entire catabolic phase, the potassiumnitrogen ratios of the losses were 2.1, 1.9, 2.6, 1.0, and $1.4 \mathrm{mEq}$. per gm., respectively, and, during the same period, the phosphorus-nitrogen ratios (corrected for calcium) were $1: 37,1: 38,1: 37$, $1: 47$, and $1: 36$, respectively (Table I). Whole tissue catabolism alone would be expected to yield a potassium-nitrogen ratio of approximately 3.0 $\mathrm{mEq}$. per gm. and a phosphorus-nitrogen ratio of $1: 15$. If the nitrogen losses are considered to be derived from whole tissue catabolism on one hand and catabolism of tissues containing nitrogen but neither potassium nor phosphorus on the other, the theoretical potassium and phosphorus-free nitrogen losses can be estimated (Table I). In some of the patients, these estimates based on potassium and on phosphorus were in good agreement (patients 4 and 5), while in others the agreement was poor.

In the anabolic phase, the mineral ratios could be expected to approximate those observed in the catabolic phase. For the anabolic phase taken as a whole, potassium-nitrogen ratios were 2.4, 5.2, $3.5,6.8$, and 5.0, respectively, and the phosphorusnitrogen ratios (corrected for calcium) were $1: 13$, $1: 9,1: 27,1: 23$, and $1: 11$, respectively. The expected anabolic ratio was approximated only in patients 3 and 4, with respect to phosphorus and nitrogen; the phosphorus-nitrogen ratio in patients 1,2 , and 5 , as well as the potassium-nitrogen ratio in patients 2 through 5 were the reverse of the expected.

\section{Fat}

Changes in fat stores were estimated for the catabolic and anabolic phases by comparing the observed weight changes with the weight changes predicted on the basis of the nitrogen balance. The electrolyte balances were not used as a measure of changes in the body fluid compartments because of the inaccuracy of the sodium and chloride balances that resulted from sweat loss. In order to avoid the cumulative errors in the electrolyte balance, the two weights used for calculating 
the weight change were chosen so that they coincided with a time when the patients were in normal fluid balance as judged by clinical criteria. This could be readily accomplished at the end of the catabolic phase and at an appropriate time chosen during the anabolic phase. Since the patient's preburn weight was not always accurately known, the preburn weight was determined from the first weight determination performed on the ward (usually within the first 24 hours after burning) corrected for the fluid balance from the time of injury until the time of the first weight determination.

The data in Table II were calculated on the assumption that $1 \mathrm{gm}$. of nitrogen is equivalent to $30 \mathrm{gm}$. of tissue. Substantial fat losses appear to have occurred in both the catabolic and anabolic phases.

\section{DISCUSSION}

The problems inherent in metabolic studies in burned patients are readily apparent. Foremost among these are the impossibility of maintaining a constant intake and the necessity for measuring the exudate. Hemolysis of considerable degree during the postburn period introduces a variable in the nitrogen balance that cannot be assessed. Treatment necessitates frequent transfusions at varying intervals of time throughout the course of illness, and failure to include red cell nitrogen as part of the nitrogen intake causes a sizable cumulative error. These difficulties are compensated for, at least in part, by the magnitude of the metabolic changes that take place and by the length of observation used in this study.

\section{Balances}

The potassium balance during the catabolic phase is of particular interest and may be divided into three periods : 1) Immediately after burning, potassium balance was negative. This was associated with low potassium intakes in all patients. 2) Within a few days, the extent of negative potassium balance was markedly lessened, and potassium balance became positive at a very early time if liberal amounts of potassium were given. 3) In the later part of the catabolic phase, potas-
TABLE II

Estimated body fat changes during the catabolic and anabolic phases

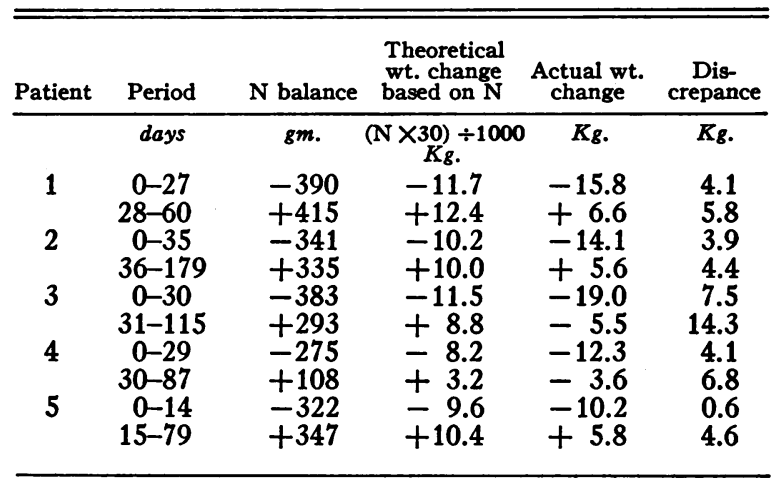

sium balance became negative again. At this time, potassium balance appeared to be less influenced by potassium intake, and large potassium intakes were frequently associated with negative balance.

Interpretation of the balances of calcium and phosphorus in the absence of constant intakes of these minerals is difficult, since changes in the intake are only slowly reflected in the fecal excretion (fecal lag). In the present study, pronounced fluctuations in the intake were inevitable. The highly variable contributions to the output by urine and feces can be seen in the detailed data. ${ }^{2}$ The long fecal collection periods tended to compensate partly for fecal lag. In the correlation charts, the highly variable nature of calcium and phosphorus balance data becomes less apparent owing to the pooling of data.

Since preburn control balances are not available, the cumulative calcium balances cannot be compared with the studies on 6 to 7 weeks of immobilization that Deitrick, Whedon, and Shorr performed in healthy adult male subjects (16). There is no evidence, however, that the calcium losses in the burned patients were substantially greater than those expected as a result of prolonged immobilization.

The urinary calcium excretion was unusually high in all patients except patient 4. This was in general accompanied by a high urinary phosphorus excretion. ${ }^{4}$ In the presence of such findings, there is a serious danger of renal calculus for-

4 It is known that renal calcinosis and hypercalcemia with eventual renal failure are often associated with urine calcium levels of this magnitude. Plasma calcium levels and renal functions were not measured in these patients. 
mation. ${ }^{5}$ Although the incidence of renal calculi appears to be small, the advisability of giving diets with a high calcium and phosphorus content is open to question in view of the findings presented here.

Changes in the magnesium balance reflected, to a large extent, changes in fecal magnesium excretion. The latter was distinctly influenced by the level of magnesium intake. It was of interest that, in several study periods, the fecal magnesium was greater than the magnesium intake. This indicates either that magnesium was excreted into the gastrointestinal tract or that fecal excretion of previously ingested magnesium was greatly delayed. Strongly positive magnesium balance was observed only in patient 1 during the latter part of the study. This resulted from a slightly decreased fecal magnesium excretion that was associated with a greatly increased magnesium intake.

\section{Correlations and changes in body composition}

The most striking and consistent change in the balances was the failure of the early potassium and phosphorus balances to correlate with the nitrogen balance. When the entire catabolic phase is considered, the catabolized tissue contained less potassium and phosphorus in relationship to nitrogen than normal protoplasm. This may be explained as the loss of a relatively nitrogen-rich tissue or as loss of protoplasm with deposition of potassium and phosphorus, either in intracellular fluid or with glycogen. Since collagen and skin contain a large amount of nitrogen in relation to potassium, lysis of large amounts of these tissues may account for part of the nitrogen lost in excess of that expected by the potassium balance. $\mathrm{Ca}$ tabolism of plasma proteins, liver proteins, and other reserve protein stores may explain part of

\footnotetext{
5 In a review of 650 burned patients, most of whom were immobilized for at least three months and frequently much longer, there was one patient who had bilateral renal calculi, two patients who had a bladder calculi, and two patients in whom renal calculus formation was suspected clinically but not confirmed roentgenologically. The incidence of asymptomatic calculus formation in the genito-urinary tract is not known. Nearly all patients were given diets with high calcium and phosphorus contents similar to those used in the present study. The calcium and phosphorus contents of the diets are high because milk and milk products are used as supplements to the regular diet.
}

the large nitrogen losses in excess of potassium and phosphorus during the early catabolic phase.

The ratio of nitrogen to other intracellular constituents during the anabolic phase would be expected to be the same as that during the catabolic phase. Actually, these ratios were often the reverse of the expected during the anabolic phase. This may be explained partly by the fact that the catabolic phase was studied in its entirety while the anabolic phase certainly extended far beyond the completion of these studies. None of the patients had achieved nitrogen equilibrium by the time the studies ended. When patients 1 and 5 were discharged from the hospital, the nitrogen losses incurred after injury had been replaced in both patients so that the cumulative nitrogen balance from the time of injury to discharge approached zero. Two months after discharge, additional studies were performed in these patients for four 5-day metabolic periods. At that late date, both patients were still in significantly positive nitrogen, potassium, phosphorus, calcium, and magnesium balances. Thus, convalescence in these patients was characterized by mineral retention in excess of the amounts present in the body before injury. This is most surprising since the capacity for mineral storage of healthy adults is quite limited.

\section{Clinical data}

During the catabolic phase, areas of partialthickness skin loss healed satisfactorily in all patients, and skin grafts took well in patients 2,3 , and 5, who were grafted during this period. During the anabolic phase, clinical correlations between nitrogen balance and a good healing capacity could not always be established. Positive nitrogen balance per se does not appear to insure proper healing, and other factors, such as degree of depletion of body proteins and fat stores, endocrine changes, and changes in the wound itself, probably play dominant roles in the healing process.

\section{SUM MARY}

1. The balances of nitrogen, potassium, phosphorus, calcium, magnesium, sodium, and chloride were measured in five severely burned patients from the time of injury to complete healing. 
Individual studies varied in length from 60 to 180 days.

2. The nitrogen losses incurred during the catabolic phase could not be accounted for on the basis of whole tissue dissolution: the negative nitrogen balance was greater than could be explained by either the potassium balance or the phosphorus balance corrected for calcium.

3. In general, magnesium balance paralleled the nitrogen balance in direction, but the nitrogenmagnesium ratio of catabolized tissue and anabolized tissue varied greatly.

4. Body fat losses, estimated from nitrogen balance and weight changes, appeared to occur in all patients during both the catabolic and the anabolic phases.

\section{ACKNOWLEDGMENT}

We wish to express our gratitude to Drs. Harry S. Soroff, Benjamin A. Barnes, Melvin S. Schwartz, C. F. Liedberg, and Irving Gray for their help and advice. Captains Helen Donnelly, Rebecca Holland, Violet Green, Margaret Maher, and Edith Bonnet and Lieutenant Alice Edelen were responsible for carrying out an exacting metabolic routine. Mr. William Creech and Mr. Emil Shaw gave valuable technical assistance. We are particularly indebted to Dr. William H. Amspacher, formerly Commanding Officer of the Surgical Research Unit, whose sustained support and encouragement made these studies possible.

\section{APPENDIX}

Patient 1. This 32-year-old Negro airman received partial-thickness (second degree) burns of 70 per cent of the body surface when a relative attempted to kill him by pouring boiling water over him while he was sleeping in the nude. Before injury, the patient had been in excellent health.

Physical examination revealed a well-developed, wellnourished man who had burns involving the face, both upper extremities, portions of the anterior and posterior aspects of the trunk, and both thighs. Local care consisted of superficial debridement and cleansing of all burned areas, and the application of compression dressings over all areas except the face and the anterior aspect of the trunk; these were treated by the exposure method. During the first 48 hours after burning, the patient was given intravenously $1500 \mathrm{ml}$. of blood, 1500 ml. of plasma, $1000 \mathrm{ml}$. of 0.9 per cent saline, $9000 \mathrm{ml}$. of lactated-Ringer's solution, and $1000 \mathrm{ml}$. of 5 per cent dextrose in water. On this regimen, the urinary output was maintained at approximately $50 \mathrm{ml}$. per hour, and signs and symptoms of circulatory collapse were not observed. Swelling of the wounds began immediately after injury and increased progressively until the 8th post- burn day. Until this time, the patient's clinical course was characterized by progressive deterioration as evidenced by periods of disorientation, abdominal distention, and increasing fever ( $104^{\circ} \mathrm{F}$. on fifth postburn day). On the 8th postburn day, a diuresis occurred, the urine volumes being $5180 \mathrm{ml}$., $5140 \mathrm{ml}$., $3600 \mathrm{ml}$., $5160 \mathrm{ml}$., and $6440 \mathrm{ml}$. on the 8th, 9th, 10th, 11th, and 12th postburn days, respectively. Concomitantly, the sensorium cleared, abdominal distention ceased, and the temperature became normal. Thereafter, the patient felt well and ingested increasing quantities of food.

The wounds healed satisfactorily so that most burned areas were epithelized within 3 weeks. Complete healing was noted on the 33rd postburn day. Convalescence was complicated on the 22nd postburn day by what was believed to be phlebothrombosis of the leg veins and a small pulmonary infarct. Heparin treatment was given. The patient was ambulatory on the 35th postburn day. He returned to the hospital for follow-up studies 106 days after injury. At that time, his weight had returned to preburn levels.

Patient 2. This 24-year-old white airman received extensive burns when a kerosene stove exploded in his trailer. The patient's wife was fatally burned in the same accident. Before injury, the patient had been in good health except for minor psychiatric difficulties.

Physical examination revealed a well-developed, wellnourished man who had burns extending over 45 per cent of the body surface. Full-thickness (third degree) burns were noted on the face, the scalp, and both upper extremities, a total of 20 per cent of the body surface. Partial-thickness burns involved the trunk and the anterior aspect of the thighs. Local care consisted of superficial debridement and cleansing of all burned areas, exposure treatment of the face, and compression dressings over the other burned areas. A tracheotomy was performed a few hours after injury.

Supportive therapy during the first 48 hours consisted of $750 \mathrm{ml}$. of plasma, $1300 \mathrm{ml}$. of 0.9 per cent saline, 5000 $\mathrm{ml}$. of lactated-Ringer's solution, and $1000 \mathrm{ml}$. of 5 per cent dextrose in water. On this regimen, the urinary output was maintained at approximately $40 \mathrm{ml}$. per hour, and signs and symptoms of circulatory collapse did not develop. Fever $\left(105^{\circ}\right.$ F.) became evident on the 5th day postburn, and on the 9th postburn day, a diagnosis of septicemia caused by Micrococcus-pyogenes, var. aureus, coagulase positive, was established by blood culture. Therapy consisted of Chloramphenicol intravenously. The temperature gradually receded to between $100^{\circ} \mathrm{F}$. and $101^{\circ} \mathrm{F}$., and the last positive blood culture was obtained on the 12th postburn day.

The patient was disoriented immediately after injury and had episodes of disorientation and hallucinations for the first month. It was believed that these were caused by his inability to see (edema of lids and, later, tarsorrhaphy) and his concern about his wife's death and his disfigurement, which accentuated psychiatric difficulties that were present before injury.

The partial-thickness burns were healed within a month after injury. Many skin grafts failed to take ow- 
ing to excessive wound suppuration. Convalescence was complicated by homologous serum hepatitis. This was diagnosed on the basis of jaundice and liver function tests on the 95th postburn day and delayed further skin grafting.

Skin grafts: 16th, 32nd, 59th, and 136th postburn days. General anesthesia for dressing changes : 22nd, 28th, 29th, 38th, 43rd, 50th, 57th, 63rd, 72nd, 109th, and 156th postburn days. Blood transfusions: 5 th (2 units), 15th (1 unit), 16th (1 unit), 59th (2 units), 73rd (2 units), 136th (2 units), and 156th (1 unit) -a total of 11 units.

Patient 3. This 20-year-old white airman received burns over 25 per cent of the body surface when a transport plane, in which he was a passenger, crashed after take-off. Before injury, the patient had been in excellent health.

Physical examination revealed a well-developed, wellnourished man who had deep full-thickness burns of the face, both upper extremities, both thighs, and the anterior aspect of the trunk. Full-thickness burns extended over 23 per cent of the body surface and partial-thickness burns over 2 per cent. After superficial debridement and cleansing, compression dressings were applied to all burned areas except the face, which was treated by the exposure method. A tracheotomy was performed a few hours after injury.

During the first 48 hours, $500 \mathrm{ml}$. of plasma, $2000 \mathrm{ml}$. of blood, $500 \mathrm{ml}$. of dextran, $1000 \mathrm{ml}$. of Ringer's solution, $3000 \mathrm{ml}$. of 0.9 per cent saline, $1850 \mathrm{ml}$. of lactatedRinger's solution, and $3450 \mathrm{ml}$. of 5 per cent dextrose in water were given as supportive therapy. This large volume of fluids, which in retrospect appears excessive, was given because the extent of burn was overestimated initially. The urinary output was in excess of $150 \mathrm{ml}$. per hour on many occasions during the first 48 hours; signs and symptoms of circulatory collapse did not develop. Septicemia caused by Alkaligenes faecalis and coagulase negative micrococci was diagnosed by blood culture on the 4th postburn day, a sudden temperature rise to $105^{\circ} \mathrm{F}$. having aroused suspicion of this complication. On therapy with erythromycin, the blood culture became negative and the fever receded.

The patient's hospital course was complicated by repeated graft failures owing to Group A beta hemolytic streptococcal colonization of the wounds.

Skin grafts : 23rd, 32nd, 69th, and 96th postburn days. Dressing changes under anesthesia: 13th, 16th, 19th, 30th, 38th, 45th, 48th, 54th, 67th, 73rd, and 81st postburn days. Blood transfusions: 13th (1 unit), 31st (1 unit), 32nd (1 unit), 55th (1 unit), 68th (2 units), and 69th (2 units) postburn days. Total blood transfusions -8 units.

Patient 4. This 27-year-old Negress received extensive body burns when her clothes ignited as a result of her pouring kerosene on a hot stove. She had a normal, full-term infant two and a half months before the burning accident and had noted intermittent, scanty vaginal bleeding since the delivery.

Physical examination revealed a slightly obese woman who had burns involving 55 per cent of the body surface, including 45 per cent full-thickness burns and 10 per cent partial-thickness burns. Full-thickness skin loss extended over the neck, the anterior and posterior aspects of the trunk, and the thighs; partial-thickness skin loss extended over the hands and the face. Local care consisted of superficial debridement and cleansing of all burned surfaces, and the application of compression dressings over all burned areas except the face, which was treated by the exposure method.

Supportive therapy during the first 48 hours after injury consisted of the following fluids: $1000 \mathrm{ml}$. of blood, $500 \mathrm{ml}$. of plasma, $500 \mathrm{ml}$. of dextran, $2000 \mathrm{ml}$. of 0.9 per cent saline, and $6000 \mathrm{ml}$. of lactated-Ringer's solution. On this regimen, signs and symptoms of circulatory collapse did not develop. A urine flow of approximately $50 \mathrm{ml}$. per hour during the first 48 hours and thereafter a progressively increasing rate of urine flow gave evidence of satisfactory fluid redistribution. A blood culture, taken on the 4th postburn day because of fever of $103^{\circ} \mathrm{F}$., was positive for Micrococcus pyogenes, var. aureus, coagulase positive. This microbe was sensitive in vitro to oxytetracycline, and treatment with this antibiotic, $2 \mathrm{gm}$. intravenously per day, resulted in blood stream sterilization within two days. Progressive salt and water deficits developed and escaped attention from the 6th to the 10th postburn days. When appropriate fluid therapy was given, acute gastric dilatation developed; this was treated by continuous gastric suction. From this time on, gastrointestinal atony was a problem, intermittently, throughout the patient's hospital course, and prevented the use of an adequate feeding regimen.

As a result of these complications, clinical management was made difficult. The partial-thickness burns healed satisfactorily, and grafts applied to the neck and the chest above the nipple line on the 41st postburn day took to the extent of 95 per cent. However, the donor sites (lower legs and upper arms) were converted, in large measure, to full-thickness skin loss. This conversion, which was believed to be a result of severe malnutrition, delayed further grafting. The clinical course was one of progressive deterioration. On the 86th postburn day, the patient had a cardiac arrest during induction of anesthesia. Cardiac massage was instituted and a normal sinus rhythm was resumed, but the patient did not regain consciousness and died within 12 hours. Skin graft : 41st postburn day. Dressing changes under anesthesia: 34th, 37th, 40th, 43rd, 48th, 54th, 58th, 61st, 69th, and 86th postburn days. Blood transfusions: 4th (1 unit), 5th (1 unit), 14th (1 unit), 15th (2 units), 16th (1 unit), 34th (1 unit), 41st (11/2 units), 53rd (2 units), 54th (2 units), 55th (2 units), 59th (1 unit), 84th (2 units), 85th (2 units), and 86th (2 units) postburn days-a total of $211 / 2$ units.

Patient 5. This 30-year-old white airman received burns over 35 per cent of the body surface in a nightclub fire. Before injury, the patient had been in excellent health.

Physical examination revealed a well-developed, wellnourished man who had full-thickness burns of both upper extremities (15 per cent of body surface) and partial-thickness burns of the face and the back (20 per 
cent). Local care consisted of superficial debridement and cleansing of all burned surfaces, and the application of compression dressings over all burned areas except the face, which was treated by the exposure method.

Supportive therapy during the first 48 hours consisted of $3400 \mathrm{ml}$. of blood, $1500 \mathrm{ml}$. of lactated-Ringer's solution, $1000 \mathrm{ml}$. of 10 per cent invert sugar, and 300 $\mathrm{ml}$. of 5 per cent dextrose in water. On this regimen, the urine flow was $75 \mathrm{ml}$. per hour on the average. Circulatory failure did not develop, but the patient was disoriented and restless during the first seven postburn days. On the fifth postburn day, fever of $105^{\circ} \mathrm{F}$. suggested the presence of septicemia, but several blood cultures failed to establish this diagnosis. The temperature receded to $101^{\circ} \mathrm{F}$. by the 7 th postburn day. Concomitantly, the patient became oriented and cooperative.

The subsequent clinical course was uneventful except for wound suppuration and poor graft takes as a result of colonization of the wounds by Group A beta hemolytic streptococci. This accounts for the protracted course. The partial-thickness burns were well healed by the 25th postburn day, and nearly complete skin coverage was achieved by the 50th postburn day. Skin grafts: 43rd and 70th postburn days. Dressing changes under anesthesia: 10th, 13th, 29th, 34th, 37th, and 40th postburn days. Blood transfusion: 43rd postburn day (2 units).

\section{REFERENCES}

1. Cuthbertson, D. P., Further observations on the disturbance of metabolism caused by injury, with particular reference to the dietary requirements of fracture cases. Brit. J. Surg., 1936, 23, 505.

2. Cuthbertson, D. P., McGirr, J. L., and Robertson, J. S. M., The effect of fracture of bone on the metabolism of the rat. Quart. J. Exper. Physiol., 1939, 29, 13.

3. Cuthbertson, D. P., Post-shock metabolic response. Lancet, 1942, 1, 433.

4. Peters, J. P., Nitrogen metabolism in acute and chronic disease. Ann. New York Acad. Sc., 1946, 47, 327.

5. Werner, S. C., Habif, D. V., Randall, H. T., and Lockwood, J. S., Postoperative nitrogen loss: A comparison of the effects of trauma and of caloric readjustment. Ann. Surg., 1949, 130, 688.

6. Hirshfeld, J. W., Abbott, W. E., Pilling, M. A., Heller, C. G., Meyer, F., Williams, H. H., Richards, A. J., and Obi, R., Metabolic alterations following thermal burns. III. Effect of variations in food intake on nitrogen balance of burned patients. Arch. Surg., 1945, 50, 194.

7. Moore, F. D., and Ball, M. R., The Metabolic Response to Surgery. Springfield, Ill., Charles C Thomas, 1952.

8. Howard, J. E., and Mason, R. E., Metabolic studies before and after operation of chronically-ill patients fed entirely by vein. Tr. of Thirteenth Conf. on Metabolic Aspects of Convalescence, New York, Josiah Macy, Jr. Foundation, 1946, p. 143.

9. Braasch, J. W., Bell, J. H., and Levenson, S. M., The excretion of nitrogen and electrolytes following thermal burns in the rat. Surgery, 1950, 27, 743.

10. Cope, O., Nathanson, I. T., Rourke, G. M., and Wilson, H., Metabolic observations. Symposium on the Management of the Cocoanut Grove Burns at the Massachusetts General Hospital. Ann. Surg., 1943, 117, 937.

11. Reiss, E., Stirman, J. A., Artz, C. P., Davis, J. H., and Amspacher, W. H., Fluid and electrolyte balance in burns. J.A.M.A., 1953, 152, 1309.

12. Artz, C. P., Reiss, E., Davis, J. H., and Amspacher, W. H., The exposure treatment of burns. Ann. Surg., 1953, 137, 456.

13. Pearson, E., Balikov, B., and Reiss, E., An analysis of errors contributed by the diet in metabolic studies. Metabolism, 1955, 4, 29.

14. Reifenstein, E. C., Jr., Albright, F., and Wells, S. L., The accumulation, interpretation, and presentation of data pertaining to metabolic balances, notably those of calcium, phosphorus, and nitrogen. J. Clin. Endocrinol., 1945, 5, 367.

15. Baldwin, D., Robinson, P. K., Zierler, K. L., and Lilienthal, J. L., Jr., Interrelations of magnesium, potassium, phosphorus, and creatine in skeletal muscle of man. J. Clin. Invest., 1952, 31, 850.

16. Deitrick, J. E., Whedon, G. D., and Shorr, E., Effects of immobilization upon various metabolic and physiologic functions of normal man. Am. J. Med., 1948, 4, 3. 